\title{
Overview of Innate Immunity in Drosophila
}

\author{
Taeil Kim and Young-Joon Kim* \\ Department of Biochemistry, Yonsei University, Seoul 120-749, Korea
}

Received 14 February 2005

\begin{abstract}
Drosophila protects itself from infection by microbial organisms by means of its pivotal defense, the so-called innate immunity system. This is its sole defense as it lacks an adaptive immunity system such as is found in mammals. The strong conservation of innate immunity systems in organisms from Drosophila to mammals, and the ease with which Drosophila can be manipulated genetically, makes this fly a good model system for investigating the mechanisms of virulence of a number of medically important pathogens. Potentially damaging endogenous and/or exogenous challenges sensed by specific receptors initiate signals via the Toll and/or Imd signaling pathways. These in turn activate the transcription factors Dorsal, Dorsal-related immune factor (Dif) and Relish, culminating in transcription of genes involved in the production of antimicrobial peptides, melanization, phagocytosis, and the cytoskeletal rearrangement required for appropriate responses. Clarifying the regulatory interactions between the various pathways involved is very important for understanding the specificity and termination mechanism of the immune response.
\end{abstract}

Keywords: Antimicrobial peptide, Innate immunity, Phagocytosis, Regulatory circuits, Toll/Imd

\section{Introduction}

Innate immunity is a first-line defense system of multicellular organisms mounted in response to various microbial invaders (Kimbrell and Beutler, 2001; Hoffmann, 2003). After the initial proposal by Janeway that innate immunity is the key to early detection of, and defense against, infection in mammals (Janeway, 1989), much work has been done to identify the sensing molecules and downstream components involved. Recognition of pathogen-associated molecular patterns (PAMPs)

*To whom correspondence should be addressed.

Tel: 82-2-2123-2628; Fax: 82-2-312-8834ax: 82-2-312-8834

E-mail: yjkim@yonsei.ac.kr by germline-encoded receptors is now known to initiate signaling cascades leading to the production of immune effectors such as antimicrobial peptides, cytokines, inflammatory mediators, and the activation of phagocytic and proteolytic cascades (Medzhitov and Janeway, 2000; Janeway and Medzhitov, 2002).

Only a restricted number of vertebrates have an adaptive immune system characterized by somatic rearrangement of immune receptor genes and clonal expansion of activated lymphocytes. Animals as well as plants lacking this type of adaptive immune system rely entirely on the innate system. Drosophila like other invertebrates has only an innate immune system, and has proved to be an ideal organism for screening for mutations in components involved in this system, many of which are common to all metazoa. The Drosophila system comprises three types of response; one is a humoral response dependent on the production of antimicrobial peptides in the fat body (the equivalent of the mammalian liver), the second a cellular response involving phagocytosis by plasmatocytes (Drosophila blood cell) and the third, melanization, which is believed to function in wound healing (Rizki and Rizki, 1984; Braun et al., 1998; Ferrandon et al., 1998; Tzou et al., 2000; Hoffmann and Reichhart, 2002). The sophisticated application of genetic methodology has permitted identification of at least two signaling pathways--the Toll and Imd pathways--that play pivotal roles in the production of the antimicrobial peptides by activating three NF- $\mathrm{KB}$-like factors and initiating the innate immune response (Tzou et al., 2002; Hoffmann and Reichhart, 2002; Hultmark, 2003; Hoffmann, 2003). Stimulation of the Toll pathway leads to activation of two NF-KB-like factors, Dorsal and Dif (Dorsal-related immunity factor), while the Imd pathway brings about the activation and nuclear translocation of the NF-אB-like factor, Relish. In this review, we summarize recent advances in understanding innate immunity in Drosophila.

Antimicrobial peptides and humoral response There are seven inducible antimicrobial peptides in Drosophila. They are transcribed in the fat body within hours of an immune challenge and are secreted into the blood. Drosomycin, Metchnikowin and Cecropin are active against fungi, Defensin 


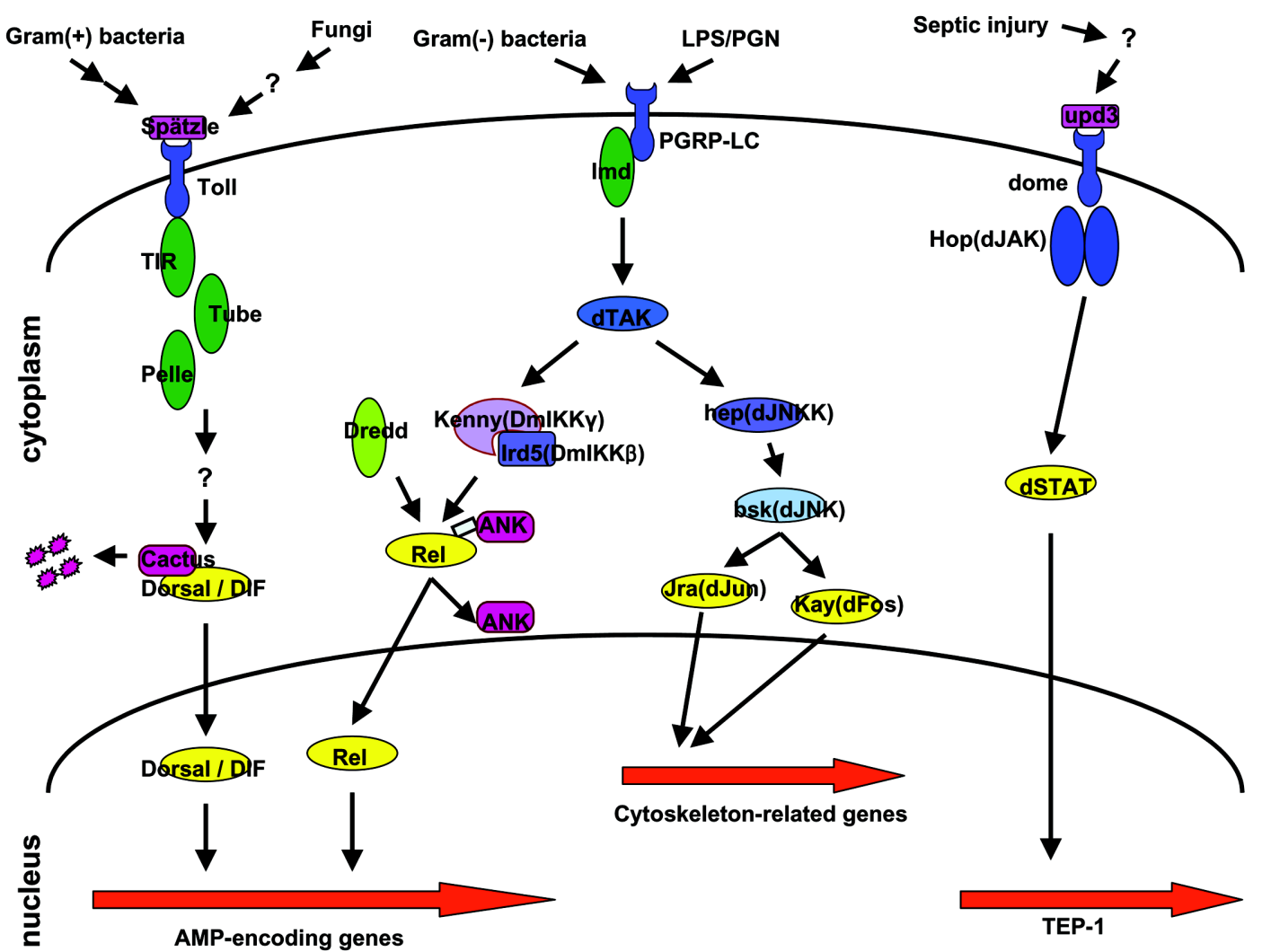

Fig. 1. The Toll, Imd and JAK-STAT pathways controlling the expression of genes related to physiological responses to infection. Spätzle is processed by a serine protease cascade upon infection and binds to Toll. This activates an intracellular signaling cascade culminating in degradation of Cactus and nuclear translocation of the NF- $\kappa B$-like transcription factors, Dorsal and Dif. The Imd pathway branches into the JNK and IKK signaling modules at dTAK1. Relish, phosphorylated by the IKK complex, is cleaved to a smaller, active form with transactivating activity in the nucleus. The JNK pathway leads to activation of dAP1 (a homo- or hetero-dimer of dJun and/or dFos) via Hep and Bsk proteins which in Drosophila are dJNKK and dJNK, respectively. In addition, a STAT dimer is translocated to the nucleus as a result of activation of JAK kinase via the cytokine class I receptor, Domeless (Dome).

and Metchnikowin against Gram-positive bacteria and Attacin, Cecropin, Diptericin and Drosocin against Gramnegative bacteria (Bulet et al., 1999; Meister et al., 2000). These peptides are small and structurally diverse molecules that work in combination to block the growth of invaders by disrupting their membranes (Lemaitre et al., 1996). The promoter regions of the antimicrobial peptide genes contain a consensus sequence element similar to that of mammalian NF- $\kappa B$. These $\kappa B$-like sites control the synthesis of antimicrobial peptides in response to the presence of bacterial cell wall components in the insect blood, and mutations in these sites impair transcription of the corresponding genes (Engstrom, 1993; Kappler et al., 1993). Dorsal, the first Drosophila NF-кB-like factor identified, is activated by Toll and regulates dorsoventral patterning in the early embryo. The requirement for $\mathrm{\kappa B}$ sites and similarities between the activation of Dorsal in the Drosophila embryo and the activation of NF- $\mathrm{BB}$ in cytokine-induced inflammation in mammals led investigators to envision a role for the dorsoventral regulatory cascade in immune defense (St. Johnston and Nusslein-Volhard, 1992; Morisato and
Anderson, 1995; Belvin and Anderson, 1996).

Hemocyte differentiation and cellular responses Cellular responses also have important roles in protecting Drosophila against infection. Drosophila blood cells are of three types. Plasmatocytes are phagocytic macrophage-like cells comprising about $90 \%$ of the blood cells. Phagocytosis by them permits rapid uptake of infectious bacteria. Lamellocytes have a flattened shape and undertake the encapsulation of larger invaders such as parasite eggs, and crystal cells provide the enzymes required for the melanization reaction (Rizki and Rizki, 1984; Lanot et al., 2001). Drosophila hematopoiesis occurs during the embryonic and larval stages. Embryonic blood cells ingest apoptotic cells by phagocytosis, and engulf microbes injected into the embryo (Hartenstein and Jan, 1992; Tepass et al., 1994; Franc et al., 1999). Lymph glands, the larval hematopoietic organs, form along with the anterior portion of the dorsal vessel in the third instar larvae. These organs disappear at the pupal stage and no hematopoietic organs have been identified at later times (Rizki and Rizki, 1984; Rugendorff et al., 1994; Lanot et al., 2001). 


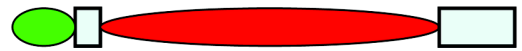

GNBP
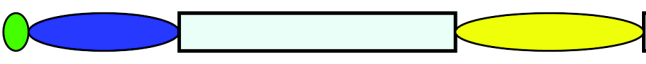

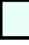
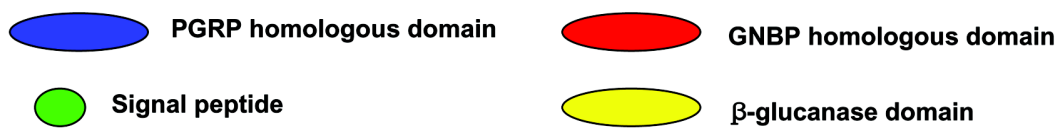

Fig. 2. Selected members of the PGRP and GNBP families. PGRP-LC, a transmembrane PGRP protein, is required for activation of the Imd pathway by Gram-negative bacteria (LCa is one of its isoforms). PGRP-SA and GNBP1 are small, secreted proteins that function in the activation of Toll by Gram-positive bacteria.

Commitment to the Drosophila hematopoietic lineage is controlled by the transcription factors Lozenge, Serpent, Ushape and Glial cell missing. The striking similarities between Drosophila Serpent, Lozenge and U-shape and the mammalian hematopoietic factors GATA, Acute Myeloid Leukemia-1 (AML1) and Friend of GATA (FOG), indicate that the molecular mechanism of blood cell lineage formation is conserved between Drosophila and mammals (Lebestky et al., 2000; Fossett et al., 2001).

Melanization When Drosophila is wounded by invaders and its cuticular barrier is broken, deposition of melanin and rapid clotting of the blood is induced (Söderhäll and Cerenius, 1998). Melanization contributes not only to wound healing but also to encapsulation of wasp eggs, and generates toxic intermediates such as reactive oxygen species (ROS) that may combat infection. The phenoloxydase required for production of melanin from dopamine is activated by a serine protease cascade (Söderhäll and Cerenius, 1998), and defects in this enzyme lead to increased sensitivity to infection (Braun et al., 1998; Rämet et al., 2002).

\section{Signaling cascades regulating humoral and cellular responses} The Toll signaling pathway was identified in parallel by biochemical studies of cytokine stimulation in mammalian systems and genetic investigations of dorsoventral patterning in Drosophila (Wasserman, 1993; O'Neill and Greene, 1998). In Drosophila, the spätzle/Toll/cactus dorsoventral regulatory gene cassette has been found to control the potent resistances to fungi and Gram-positive bacteria that depend on Dorsal and Dif. (Lemaitre et al., 1996; Meng et al., 1999; Wasserman,
2000). Drosophila Toll, the first identified Toll family member, consists of an extracellular leucine-rich repeat and intracellular signaling domains (Schneider et al., 1991). Spätzle, the ligand for Toll, is a secreted protein that is activated by proteolytic cleavage by a serine protease (Lavashina et al., 1999; Weber et al., 2003). Its binding to Toll activates the signaling cascade via dMyD88, the kinase, Pelle, a homolog of IRAK, and the adaptor, Tube. This leads to degradation of the IKB-like protein, Cactus, and nuclear translocation of the NF- $\mathrm{KB}-$ like protein, Dorsal, and Dif (Ip et al., 1993; Nicolas et al., 1998; Tauszing-Delamasure et al., 2002; Imler et al., 2002).

The response to infection by Gram-negative bacteria is controlled by a separate pathway, defined by mutations in the imd (immune deficient) gene. Imd flies have severe defects in resistance to Gram-negative bacteria but have normal responses to fungal and Gram-positive bacterial infections. The Imd pathway resembles the mammalian TNF- $\alpha$ pathway and culminates in the expression of antimicrobial peptides such as Attacin, Cecropin and Diptericin which confer substantial immunity to Gram-negative bacteria (Hoffmann, 2003; Brennan and Anderson, 2004).

The Imd pathway is initiated by activation of the peptidoglycan recognition protein (PGRP) (Choe et al., 2002; Gottar et al., 2002). After Imd was identified by studies of mutant flies with defects in the phenoloxidase cascade (Lemaitre et al., 1995), genetic analyses revealed other components of the pathway: a homolog of mammalian RIP (TNF-receptor-interacting protein), which is a death domainbearing protein (Georgel et al., 2001); dTAK1 (TGF- $\beta$ activated kinase 1), a MAP kinase kinase kinase (MAPKKK) 
(Vidal et al., 2001); two IאB kinase (IKK) complex components, namely IKKb (ird5) and IKKr (Kenny), which are homologs of mammalian IKK- $\beta$ and IKK- $/$ NEMO and probably phosphorylate Relish, an NFn- $\mathrm{KB}$ family protein that is activated by proteolytic cleavage (Rutschmann et al., 2000; Silverman et al., 2000; Lu et al., 2001). In addition, FADD functions downstream of IMD, controlling the activity of Dredd, a Drosophila caspase- 8 homolog, which acts with the IKK complex to fully activate Relish (Stoven et al., 2000; Hu et al., 2000; Leulier et al., 2002; Stoven et al., 2003).

The c-Jun N-terminal protein kinase (JNK; also known as the stress-activated protein kinase, SAPK) (Hibi et al., 1993), is a member of the mitogen-activated protein kinase (MAPK) superfamily; it participates in many processes in normal development and plays crucial roles in gene activation during the innate immune response (Stronach and Perrimon, 1999; Boutros et al., 2002). This JNK pathway is activated by cell stressors such as ultraviolet (UV) radiation, and proinflammatory cytokines and growth factors, and has been implicated in the control of diverse processes including morphogenesis, inflammation and apoptosis (Goberdhan and Wilson, 1998; Stronach and Perrimon 1999; Chang and Karin, 2001). In mammals, there is evidence for both pro-apoptotic and anti-apoptotic JNK activities (Lin, 2003), but extracellular stimuli generally activate the JNK pathway, resulting in programmed cell death (Verheij et al., 1996). In Drosophila, lipopolysaccharides (LPS) have been reported to activate JNK, which is required for induction of a subset of immune response genes (Sluss et al., 1996; Boutros et al., 2002), and homologs of many of the mammalian JNK pathway components have been identified; Hep, a MKK7 homolog, Bsk (DJNK), and Djun/Dfos, an AP-1 homolog, all of which function in dorso-ventral patterning and immunity. The JNK pathway branches from the Imd pathway at dTAK1 and participates in physiological processes such as morphological transitions during development, cell cycle regulation, apoptosis, phagocytosis and immunity.

There is recent evidence that mammalian NF- $\kappa \mathrm{B}$ negatively regulates the JNK pathway in TNF- $\alpha$-induced apoptosis (Tang et al., 2001; De Smaele et al., 2001). This type of negative crosstalk has also been found in a Drosophila cell line and in flies challenged with lipopolysaccharide (LPS) or gramnegative bacteria, and involves proteasomal degradation of dTAK1 by Relish-dependent genes (Park et al., 2004). In addition there is evidence that JNK also negatively regulates autocrine TGF- $\beta$ signaling in a murine system in conjunction with AP-1 transcription factors (Ventura et al., 2004). Although there are some indications of the activity of JNK in Drosophila, investigation of the regulatory effect of the JNK signalosome in innate immunity is rendered difficult by the fact that loss-of-function mutations in this system are usually embryonic lethal (Glise et al., 1995; Sluss et al., 1996). However using RNA interference (RNAi), which mimics lossof-function mutations, we have obtained evidence that the Drosophila JNK pathway inhibits the expression of NF- $\mathrm{KB}-$ dependent genes by recruiting the dHDAC complex to their promoters via dAP1 (Kim et al., 2005). The detection of reciprocal regulation between the Drosophila immunity pathways is very important for understanding the balance between initiation and termination of the immune response, and promises to provide insight into the mammalian counterpart of this regulatory interaction.

In mammals, local disturbances of physiological homeostasis lead to an acute and systemic reaction. In this process, IL6, produced in response to the presence of bacterial cell wall compounds such as LPS, triggers JAK-STAT signaling in hepatocytes culminating in translocation of STAT dimers to the nucleus where they activate transcription of target genes encoding acute phase proteins (Baumann and Gauldie, 1994; Alonzi et al., 2001). JAK-STAT signaling is required in the fat body of Drosophila to turn on genes, such as the stressinduced gene, totA, as well as Tepl, which encodes a thiolester-containing protein (Agaisse et al., 2003). Expression of Tepl has been shown to be constitutive in larvae with a gain-of-function mutation in JAK, and reduced in a corresponding loss-of-function mutation. This supports the evidence that the JAK-STAT pathway is activated upon immune challenge (Lagueux et al., 2000). The Drosophila hemocyte-specific cytokine-like protein, Unpaired 3 (Upd3), activates transcription of totA in the fat body via a homolog of the vertebrate cytokine class I receptor, Domeless (Dome), and this is followed by activation of the JAK-STAT pathway (Agaisse et al., 2003).

Recognition of pathogens In contrast to mammalian Tolllike receptors (TLRs), Drosophila Toll does not appear to interact directly with pathogen-associated molecular patterns (PAMPs), but is activated by Spätzle via a proteolytic cascade (Lemaitre et al., 1996). How does Drosophila recognize infection inducers and discriminate self from non-self? Two families of proteins have been implicated in pathogen recognition. First the peptidoglycan recognition protein (PGRP) was identified as a Gram-positive-binding protein and this was followed by identification of the Gram-negativebinding protein (GNBP), which binds to LPS and $\beta-1,3-$ glucan (Lee et al., 1996; Kang et al., 1998; Kim et al., 2000; Werner et al., 2000). The Drosophila genome contains 13 genes encoding PGRP family proteins, and 3 encoding GNBP family proteins. Seven of the PGRPs are small $(\sim 20 \mathrm{kDa})$ extracellular polypeptides, whereas others are larger (30 to 90 $\mathrm{kDa}$ ) and either intercellular or membrane-spanning. GNBPs are $50 \mathrm{kDa}$ proteins containing an $\mathrm{N}$-terminal $\beta$-1,3-glucan binding domain and a $\mathrm{C}$-terminal $\beta$-glucanase-like domain (Werner et al., 2000; Ochiai and Ashida, 2000). PGRP-LC, a transmembrane PGRP, is required for activation of the Imd pathway. Loss-of-function mutants of PGRL-LC are susceptible to Gram-negative bacteria but not to Gram-positives and they fail to form the antimicrobial peptides (Choe et al., 2002; Rämet et al., 2002). Another PGRP, PGRP-LE, activates the Imd pathway when it is overexpressed (Takehana et al., 2002). 
PGRP-SA, a secreted PGRP, functions in the detection of Gram-positive pathogens (Michel et al., 2001). Mutants of PGRP-SA were obtained by screening for flies defective in forming Drosomycin, which was known to be induced via the Toll pathway in response to both Gram-positive bacteria and fungi. PGRP-SA mutants are specifically susceptible to Gram-positive bacteria but resistant to fungi and Gramnegative bacteria; the induction of Drosomycin by Gramnegative or fungal infection is unaffected in these mutants, whereas its induction by Gram-positive bacteria is abolished (Michel et al., 2001; Leulier et al., 2003). The relatively large numbers of recognition molecules that have been identified help to account for the specific recognition of diverse pathogens.

\section{Conclusion}

During the last two decades, genetic and biochemical studies have uncovered the essential components of the Toll and Imd signaling pathways required for immune defense in Drosophila. However, the molecular mechanisms of other crucial responses to infection, including phagocytosis, encapsulation, melanization and coagulation, remain to be clarified. New techniques such as DNA microarrays and RNA interference, combined with the availability of the complete Drosophila genome sequence and forward and reverse genetic analysis, promise to yield insight into these other responses within the next few years.

\section{References}

Agaisse, H., Petersen, U. M., Boutros, M., Mathey-Prevot, B. and Perrimon, N. (2003) Signaling role of hemocytes in Drosophila JAK/STAT-dependent response to septic injury. Dev. Cell 5, 441-450.

Alonzi, T., Maritano, D., Gorgoni, B., Rizzuto, G., Libert, C. and Poli, V. (2001) Essential role of STAT3 in the control of the acute-phase response as revealed by inducible gene inactivation [correction of activation] in the liver. Mol. Cell. Biol. 21, 16211632.

Baumann, H. and Gauldie, J. (1994) The acute phase response. Immunol. Today 15, 74-80.

Belvin, M. P. and Anderson, K. V. (1996) A conserved signaling pathway: the Drosophila toll-dorsal pathway. Annu. Rev. Cell Dev. Biol. 12, 393-416.

Boutros, M., Agaisse, H. and Perrimon, N. (2002) Sequential activation of signaling pathways during innate immune responses in Drosophila. Dev. Cell 3, 711-722.

Braun, A., Hoffmann, J. A. and Meister, M. (1998) Analysis of the Drosophila host defense in domino mutant larvae, which are devoid of hemocytes. Proc. Natl. Acad. Sci. USA 95, 14337-14342.

Brennan, C. A. and Anderson, K. V. (2004) Drosophila: the genetics of innate immune recognition and response. Аnnu. Rev. Immunol. 22, 457-483.

Bulet, P., Hetru, C., Dimarcq, J. L. and Hoffmann, D. (1999)
Antimicrobial peptides in insects; structure and function. Dev. Comp. Immunol. 23, 329-344.

Chang, L. and Karin, M. (2001) Mammalian MAP kinase signaling cascades. Nature 410, 37-40.

Choe, K. M., Werner, T., Stoven, S., Hultmark, D. and Anderson, K. V. (2002) Requirement for a peptidoglycan recognition protein (PGRP) in Relish activation and antibacterial immune responses in Drosophila. Science 296, 359-362.

De Smaele, E., Zazzeroni, F., Papa, S., Nguyen, D. U., Jin, R., Jones, J., Cong, R. and Franzoso, G. (2001) Induction of gadd45beta by NF-kappaB downregulates pro-apoptotic JNK signaling. Nature 414, 308-313.

Engstrom, Y., Kadalayil, L., Sun, S. C., Samakovlis, C., Hultmark, D. and Faye, I. (1993) kappa B-like motifs regulate the induction of immune genes in Drosophila. J. Mol. Biol. 232, 327-333.

Ferrandon, D., Jung, A. C., Criqui, M., Lemaitre, B., UttenweilerJoseph, S., Michaut, L., Reichhart, J. and Hoffmann, J. A. (1998) A drosomycin-GFP reporter transgene reveals a local immune response in Drosophila that is not dependent on the Toll pathway. EMBO J. 17, 1217-1227.

Fossett, N., Tevosian, S. G., Gajewski, K., Zhang, Q., Orkin, S. H. and Schulz, R. A. (2001) The Friend of GATA proteins Ushaped, FOG-1, and FOG-2 function as negative regulators of blood, heart, and eye development in Drosophila. Proc. Natl. Acad. Sci. USA 98, 7342-7347.

Franc, N. C., Heitzler, P., Ezekowitz, R. A. and White, K. (1999) Requirement for croquemort in phagocytosis of apoptotic cells in Drosophila. Science 284, 1991-1994.

Georgel, P., Naitza, S., Kappler, C., Ferrandon, D., Zachary, D., Swimmer, C., Kopczynski, C., Duyk, G., Reichhart, J. M. and Hoffmann, J. A. (2001) Drosophila immune deficiency (IMD) is a death domain protein that activates antibacterial defense and can promote apoptosis. Dev. Cell 1, 503-514.

Glise, B., Bourbon, H. and Noselli, S. (1995) hemipterous encodes a novel Drosophila MAP kinase kinase, required for epithelial cell sheet movement. Cell 83, 451-461.

Goberdhan, D. C. and Wilson, C. (1998) JNK, cytoskeletal regulator and stress response kinase? A Drosophila perspective. Bioessays 20, 1009-1019.

Gottar, M., Gobert, V., Michel, T., Belvin, M., Duyk, G., Hoffmann, J. A., Ferrandon, D. and Royet, J. (2002) The Drosophila immune response against Gram-negative bacteria is mediated by a peptidoglycan recognition protein. Nature $\mathbf{4 1 6}$, 640-644.

Hartenstein, V. and Jan, Y. N. (1992) Studying Drosophila embryogenesis with P-lacZ enhancer trap lines. Rouxs Arch.Dev. Biol. 201, 194-220.

Hibi, M., Lin, A., Smeal, T., Minden, A. and Karin, M. (1993) Identification of an oncoprotein- and UV-responsive protein kinase that binds and potentiates the c-Jun activation domain. Genes Dev. 7, 2135-2148.

Hoffmann, J. A. (2003) The immune response of Drosophila. Nature 426, 33-38.

Hoffmann, J. A. and Reichhart, J. M. (2002) Drosophila innate immunity: an evolutionary perspective. Nature Immunol. 3, 121-126.

Hu, S. and Yang, X. (2000) dFADD, a novel death domaincontaining adapter protein for the Drosophila caspase DREDD. J. Biol. Chem. 275, 30761-30764. 
Hultmark, D. (2003) Drosophila immunity: paths and patterns. Curr. Opin. Immunol. 15, 12-19.

Imler, J. L. and Hoffmann, J. A. (2002) Toll receptors in Drosophila: a family of molecules regulating development and immunity. Curr. Top Microbiol. Immunol. 270, 63-79.

Ip, Y. T., Reach, M., Engstrom, Y., Kadalayil, L., Cai, H., Gonzalez-Crespo, S., Tatei, K. and Levine, M. (1993) Dif, a dorsal-related gene that mediates an immune response in Drosophila. Cell 75, 753-763.

Janeway, C. A. Jr. (1989) Approaching the asymptote? Evolution and revolution in immunology. Cold Spring Harbor Symp. Quant. Biol. 54, 1-13.

Janeway, C. A. Jr. and Medzhitov, R. (2002) Innate immune recognition. Annu. Rev. Immunol. 20, 197-216.

Kang, D., Liu, G., Lundstrom, A., Gelius, E. and Steiner, H. (1998) A peptidoglycan recognition protein in innate immunity conserved from insects to humans. Proc. Natl. Acad. Sci. USA 95, 10078-10082.

Kappler, C., Meister, M., Lagueux, M., Gateff, E., Hoffmann, J. A. and Reichhart, J. M. (1993) Insect immunity. Two 17 bp repeats nesting a kappa B-related sequence confer inducibility to the diptericin gene and bind a polypeptide in bacteriachallenged Drosophila. EMBO J. 12, 1561-1568.

Kim, T., Yoon, J., Cho, H., Lee, W. B., Kim, J., Song, Y. H., Kim, S. N., Yoon, J. H., Kim-Ha, J. and Kim, Y. J. (2005) Downregulation of lipopolysaccharide response in drosophila by negative crosstalk between the AP1 and NF-kappaB signaling modules. Nature Immunol. 6, 211-218.

Kim, Y. S., Ryu, J. H., Han, S. J., Choi, K. H., Nam, K. B., Jang, I. H., Lemaitre, B., Brey, P. T. and Lee, W. J. (2000) Gramnegative bacteria-binding protein, a pattern recognition receptor for lipopolysaccharide and beta-1,3-glucan that mediates the signaling for the induction of innate immune genes in Drosophila melanogaster cells. J. Biol. Chem. 275, 3272132727.

Kimbrell, D. A. and Beutler, B. (2001) The evolution and genetics of innate immunity. Nat. Rev. Genet. 2, 256-267.

Lagueux, M., Perrodou, E., Levashina, E. A., Capovilla, M. and Hoffmann, J. A. (2000) Constitutive expression of a complement-like protein in toll and JAK gain-of-function mutants of Drosophila. Proc. Natl. Acad. Sci. USA 97, 1142711432.

Lanot, R., Zachary, D., Holder, F. and Meister, M. (2001) Postembryonic hematopoiesis in Drosophila. Dev. Biol. 230, 243-257.

Lebestky, T., Chang, T., Hartenstein, V. and Banerjee, U. (2000) Specification of Drosophila hematopoietic lineage by conserved transcription factors. Science 288, 146-149.

Lee, W. J., Lee, J. D., Kravchenko, V. V., Ulevitch, R. J. and Brey, P. T. (1996) Purification and molecular cloning of an inducible gram-negative bacteria-binding protein from the silkworm, Bombyx mori. Proc. Natl. Acad. Sci. USA 93, 78887893.

Lemaitre, B., Kromer-Metzger, E., Michaut, L., Nicolas, E., Meister, M., Georgel, P., Reichhart, J. M., and Hoffmann, J. A. (1995) A recessive mutation, immune deficiency (imd), defines two distinct control pathways in the Drosophila host defense. Proc. Natl. Acad. Sci. USA 92, 9465-9469.

Lemaitre, B., Nicolas, E., Michaut, L., Reichhart, J. M. and Hoffmann, J. A. (1996) The dorsoventral regulatory gene cassette spätzle/Toll/cactus controls the potent antifungal response in Drosophila adults. Cell 86, 973-983.

Leulier, F., Parquet, C., Pili-Floury, S., Ryu, J. H., Caroff, M., Lee, W. J., Mengin-Lecreulx, D. and Lemaitre, B. (2003) The Drosophila immune system detects bacteria through specific peptidoglycan recognition. Nature Immunol. 4, 478-484.

Leulier, F., Vidal, S., Saigo, K., Ueda, R. and Lemaitre, B. (2002) Inducible expression of double-stranded RNA reveals a role for dFADD in the regulation of the antibacterial response in Drosophila adults. Curr. Biol. 12, 996-1000.

Levashina, E. A., Langley, E., Green, C., Gubb, D., Ashburner, M., Hoffmann, J. A. and Reichhart, J. M. (1999) Constitutive activation of toll-mediated antifungal defense in serpin-deficient Drosophila. Science 285, 1917-1919.

Lin, A. (2003) Activation of the JNK signaling pathway: breaking the brake on apoptosis. Bioessays 25, 17-24.

Lu, Y., Wu, L. P. and Anderson, K. V. (2001) The antibacterial arm of the drosophila innate immune response requires an IkappaB kinase. Genes Dev. 15, 104-110.

Medzhitov, R. and Janeway, C. Jr. (2000) Innate immunity. $N$. Engl. J. Med. 343, 338-344.

Meister, M., Hetru, C. and Hoffmann, J. A. (2000) The antimicrobial host defense of Drosophila. Curr. Top. Microbiol. Immunol. 248, 17-36.

Meng, X., Khanuja, B.S. and Ip, Y.T. (1999) Toll receptormediated Drosophila immune response requires Dif, an NFkappaB factor. Genes Dev. 13, 792-797.

Michel, T., Reichhart, J. M., Hoffmann, J. A. and Royet, J. (2001) Drosophila Toll is activated by Gram-positive bacteria through a circulating peptidoglycan recognition protein. Nature $\mathbf{4 1 4}$, 756-759.

Morisato, D. and Anderson, K. V. (1995) Signaling pathways that establish the dorsal-ventral pattern of the Drosophila embryo. Annu. Rev. Genet. 29, 371-399.

Nicolas, E., Reichhart, J. M., Hoffmann, J. A. and Lemaitre, B. (1998) In vivo regulation of the IkappaB homologue cactus during the immune response of Drosophila. J. Biol. Chem. 273, 10463-10469.

ONeill, L. A. and Greene, C. (1998) Signal transduction pathways activated by the IL-1 receptor family: ancient signaling machinery in mammals, insects, and plants. J. Leukoc. Biol. 63, 650-657.

Ochiai, M. and Ashida, M. (2000) A pattern-recognition protein for beta-1,3-glucan. The binding domain and the cDNA cloning of beta-1,3-glucan recognition protein from the silkworm, Bombyx mori. J. Biol. Chem. 275, 4995-5002.

Park, J. M., Brady, H., Ruocco, M. G., Sun, H., Williams, D., Lee, S. J., Kato, T. Jr., Richards, N., Chan, K., Mercurio, F., Karin, M. and Wasserman, S. A. (2004) Targeting of TAK1 by the NF-kappa B protein Relish regulates the JNK-mediated immune response in Drosophila. Genes Dev. 18, 584-594.

Rämet, M., Lanot, R., Zachary, D. and Manfruelli, P. (2002) JNK signaling pathway is required for efficient wound healing in Drosophila. Dev. Biol. 241, 145-156.

Rämet, M., Manfruelli, P., Pearson, A., Mathey-Prevot, B. and Ezekowitz, R. A. (2002) Functional genomic analysis of phagocytosis and identification of a Drosophila receptor for $\mathrm{E}$. coli. Nature 416, 644-648.

Rizki, T. M. and Rizki, R. M. (1984) The cellular defense system of Drosophila melanogaster; in Insect Ultrastructure, King, R. 
C. and Akai, H. H. (eds.), pp. 579-604, Plenum, New York, USA.

Rizki, R. M. and Rizki, T. M. (1984) Selective destruction of a host blood cell type by a parasitoid wasp. Proc. Natl. Acad. Sci. USA 81, 6154-6158.

Rugendorff, A., Younossi-Hartenstein, A. and Hartenstein, V. (1994) Embryonic orgin and differentiation of the Drosophila heart. Rouxs Arch. Dev. Biol. 203, 266-280.

Rutschmann, S., Jung, A. C., Zhou, R., Silverman, N., Hoffmann, J. A. and Ferrandon, D. (2000) Role of Drosophila IKK gamma in a toll-independent antibacterial immune response. Nature Immunol. 1, 342-347.

Schneider, D. S., Hudson, K. L., Lin, T. Y. and Anderson, K. V. (1991) Dominant and recessive mutations define functional domains of Toll, a transmembrane protein required for dorsalventral polarity in the Drosophila embryo. Genes Dev. 5, 797807.

Silverman, N., Zhou, R., Stoven, S., Pandey, N., Hultmark, D. and Maniatis, T. (2000) A Drosophila IkappaB kinase complex required for Relish cleavage and antibacterial immunity. Genes Dev. 14, 2461-247.

Sluss, H. K., Han, Z., Barrett, T., Davis, R. J. and Ip, Y. T. (1996) A JNK signal transduction pathway that mediates morphogenesis and an immune response in Drosophila. Genes Dev. 10, 2745-2758.

Söderhäll, K. and Cerenius, L. (1998) Role of the prophenoloxidase-activating system in invertebrate immunity. Curr. Opin. Immunol. 10, 23-28.

St. Johnston, D. and Nusslein-Volhard, C. (1992) The origin of pattern and polarity in the Drosophila embryo. Cell 68, 201219.

Stöven, S., Ando, I., Kadalayil, L., Engstrom, Y. and Hultmark, D. (2000) Activation of the Drosophila NF-kappaB factor Relish by rapid endoproteolytic cleavage. EMBO Rep. 1, 347-352.

Stöven, S., Silverman, N., Junell, A., Hedengren-Olcott, M., Erturk, D., Engstrom, Y., Maniatis, T. and Hultmark, D. (2003) Caspase-mediated processing of the Drosophila NF-kappaB factor Relish. Proc. Natl. Acad. Sci. USA 100, 5991-5996.

Stronach, B. E. and Perrimon, N. (1999) Stress signaling in Drosophila. Oncogene 18, 6172-6182.

Takehana, A., Katsuyama, T., Yano, T., Oshima, Y., Takada, H., Aigaki, T. and Kurata, S. (2002) Overexpression of a patternrecognition receptor, peptidoglycan-recognition protein-LE, activates imd/relish-mediated antibacterial defense and the prophenoloxidase cascade in Drosophila larvae. Proc. Natl.
Acad. Sci. USA 99, 13705-13710.

Tang, G., Minemoto, Y., Dibling, B., Purcell, N. H., Li, Z., Karin, M. and Lin, A. (2001) Inhibition of JNK activation through NF-kappaB target genes. Nature 414, 313-317.

Tauszig-Delamasure, S., Bilak, H., Capovilla, M., Hoffmann, J. A. and Imler, J. L. (2002) Drosophila MyD88 is required for the response to fungal and Gram-positive bacterial infections. Nature immunol. 3, 91-97.

Tepass, U., Fessler, L. I., Aziz, A. and Hartenstein, V. (1994) Embryonic origin of hemocytes and their relationship to cell death in Drosophila. Development 120, 1829-1837.

Tzou, P., De Gregorio, E. and Lemaitre, B. (2002) How Drosophila combats microbial infection: a model to study innate immunity and host-pathogen interactions. Curr. Opin. Microbiol. 5, 102-110.

Tzou, P., Ohresser, S., Ferrandon, D., Capovilla, M., Reichhart, J. M., Lemaitre, B., Hoffmann, J. A. and Imler, J. L. (2000) Tissue-specific inducible expression of antimicrobial peptide genes in Drosophila surface epithelia. Immunity 13, 737-748.

Ventura, J. J., Kennedy, N. J., Flavell, R. A. and Davis, R. J. (2004) JNK regulates autocrine expression of TGF-beta1. Mol. Cell 15, 269-278.

Verheij, M., Bose, R., Lin, X. H., Yao, B., Jarvis, W. D., Grant, S., Birrer, M. J., Szabo, E., Zon, L. I., Kyriakis, J. M., Haimovitz-Friedman, A., Fuks, Z. and Kolesnick, R. N. (1996) Requirement for ceramide-initiated SAPK/JNK signalling in stress-induced apoptosis. Nature 380, 75-79.

Vidal, S., Khush, R. S., Leulier, F., Tzou, P., Nakamura, M. and Lemaitre, B. (2001) Mutations in the Drosophila dTAK1 gene reveal a conserved function for MAPKKKs in the control of rel/NFkappaB-dependent innate immune responses. Genes Dev. 15, 1900-1912.

Wasserman, S. A. (1993) A conserved signal transduction pathway regulating the activity of the rel-like proteins dorsal and NFkappa B. Mol. Biol. Cell 4, 767-771.

Wasserman, S. A. (2000) Toll signaling: the enigma variations. Curr. Opin. Genet. Dev. 10, 497-502.

Weber, A. N., Tauszig-Delamasure, S., Hoffmann, J. A., Lelievre, E., Gascan, H., Ray, K. P., Morse, M. A., Imler, J. L. and Gay, N. J. (2003) Binding of the Drosophila cytokine Spätzle to Toll is direct and establishes signaling. Nature Immunol. 4, 794-800.

Werner, T., Liu, G., Kang, D., Ekengren, S., Steiner, H. and Hultmark, D. (2000) A family of peptidoglycan recognition proteins in the fruit fly Drosophila melanogaster. Proc. Natl. Acad. Sci. USA 97, 13772-13777. 